\title{
Reactive Desorption of CO Hydrogenation Products under Cold Pre-stellar Core Conditions
}

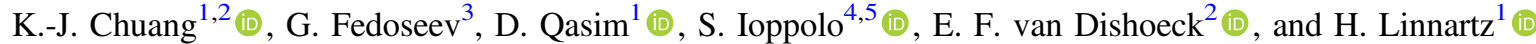 \\ ${ }^{1}$ Sackler Laboratory for Astrophysics, Leiden Observatory, Leiden University, P.O. Box 9513, NL-2300 RA Leiden, The Netherlands; chuang@ strw.leidenuniv.nl \\ ${ }^{2}$ Leiden Observatory, Leiden University, P.O. Box 9513, NL-2300 RA Leiden, The Netherlands \\ ${ }^{3}$ INAF-Osservatorio Astrofisico di Catania, via Santa Sofia 78, 95123 Catania, Italy \\ ${ }^{4}$ School of Electronic Engineering and Computer Science, Queen Mary University of London, Mile End Road, London E1 4NS, UK \\ ${ }^{5}$ School of Physical Sciences, The Open University, Walton Hall, Milton Keynes MK7 6AA, UK \\ Received 2017 November 21; revised 2017 December 12; accepted 2017 December 14; published 2018 January 26
}

\begin{abstract}
The astronomical gas-phase detection of simple species and small organic molecules in cold pre-stellar cores, with abundances as high as $\sim 10^{-8}-10^{-9} n_{\mathrm{H}}$, contradicts the generally accepted idea that at $10 \mathrm{~K}$, such species should be fully frozen out on grain surfaces. A physical or chemical mechanism that results in a net transfer from solid-state species into the gas phase offers a possible explanation. Reactive desorption, i.e., desorption following the exothermic formation of a species, is one of the options that has been proposed. In astronomical models, the fraction of molecules desorbed through this process is handled as a free parameter, as experimental studies quantifying the impact of exothermicity on desorption efficiencies are largely lacking. In this work, we present a detailed laboratory study with the goal of deriving an upper limit for the reactive desorption efficiency of species involved in the $\mathrm{CO}-\mathrm{H}_{2} \mathrm{CO}-\mathrm{CH}_{3} \mathrm{OH}$ solid-state hydrogenation reaction chain. The limit for the overall reactive desorption fraction is derived by precisely investigating the solid-state elemental carbon budget, using reflection absorption infrared spectroscopy and the calibrated solid-state band-strength values for $\mathrm{CO}, \mathrm{H}_{2} \mathrm{CO}$ and $\mathrm{CH}_{3} \mathrm{OH}$. We find that for temperatures in the range of 10 to $14 \mathrm{~K}$, an upper limit of $0.24 \pm 0.02$ for the overall elemental carbon loss upon $\mathrm{CO}$ conversion into $\mathrm{CH}_{3} \mathrm{OH}$. This corresponds with an effective reaction desorption fraction of $\leqslant 0.07$ per hydrogenation step, or $\leqslant 0.02$ per $\mathrm{H}$-atom induced reaction, assuming that $\mathrm{H}$-atom addition and abstraction reactions equally contribute to the overall reactive desorption fraction along the hydrogenation sequence. The astronomical relevance of this finding is discussed.
\end{abstract}

Key words: astrochemistry - infrared: ISM - ISM: molecules - methods: laboratory: solid state

\section{Introduction}

Surface chemistry in the earliest phase of molecular cloud evolution is determined by a rather low particle density $\left(\sim 10^{3}-10^{4} \mathrm{~cm}^{-3}\right)$ at temperatures around $\lesssim 15 \mathrm{~K}$. In such environments, chemical processes on dust grains are largely dominated by $\mathrm{H}$-atom addition reactions, forming an $\mathrm{H}_{2} \mathrm{O}$-rich polar ice layer on silicate dust grains by recombining oxygen and hydrogen atoms (Tielens \& Hagen 1982; Tielens et al. 1991; Ioppolo et al. 2008, 2010; Miyauchi et al. 2008; Cuppen et al. 2010; Öberg et al. 2011; van Dishoeck et al. 2013; Boogert et al. 2015; Linnartz et al. 2015). During this stage, other molecules, like $\mathrm{NH}_{3}$ and $\mathrm{CH}_{4}$, also form in $\mathrm{N}+\mathrm{H}$ and $\mathrm{C}+\mathrm{H}$ addition reactions (Hasegawa et al. 1992; Hiraoka et al. 1995, 1998; Hidaka et al. 2011; Fedoseev et al. 2015). In the next phase, temperatures become as low as $\sim 10 \mathrm{~K}$ and densities increase $\left(\sim 10^{4-5} \mathrm{~cm}^{-3}\right)$; gaseous $\mathrm{CO}$ accretes onto the pre-formed $\mathrm{H}_{2} \mathrm{O}$-rich ice and forms a $\mathrm{CO}$-rich apolar ice coating (Pontoppidan 2006), an event often referred to as the "catastrophic CO freeze-out stage." The timescale for the CO freeze-out phase is about $10^{4-5}$ years $\left(1 \times 10^{9} / n_{\mathrm{H}}\right.$ years where $n_{\mathrm{H}}=2 n\left(\mathrm{H}_{2}\right)+n(\mathrm{H})$, Willacy \& Millar 1998), which is shorter than the typical lifetime of a low-mass prestellar core $\left(\sim 4.5 \times 10^{5}\right.$ years, Enoch et al. 2008). The CO coating is regarded as a starting point in the hydrogenation scheme that leads primarily to the formation of $\mathrm{H}_{2} \mathrm{CO}$ and $\mathrm{CH}_{3} \mathrm{OH}$ through successive $\mathrm{H}$-atom additions. This reaction scheme has been studied in much detail before, in a gas-grain model by Tielens \& Hagen (1982), in astrochemical simulations and theoretical studies (Charnley et al. 1997; Cuppen et al. 2009; Chang \&
Herbst 2012) and in a number of systematic laboratory experiments (Hiraoka et al. 1994; Watanabe \& Kouchi 2002; Zhitnikov \& Dmitriev 2002; Fuchs et al. 2009). The solid-state laboratory and astrochemical modeling conclusions are in agreement with the observed $\mathrm{CH}_{3} \mathrm{OH}$ ice and gas abundances in star-forming regions that cannot be explained through a pure gas-phase radiative association route (Garrod et al. 2006; Geppert et al. 2006). Analysis of Very Large Telescope ice data shows that $\mathrm{CH}_{3} \mathrm{OH}$ and $\mathrm{CO}$ must be mixed in interstellar ices and exist in a water poor environment (Cuppen et al. 2011; Penteado et al. 2015), fully consistent with the picture that methanol is formed via sequential hydrogenation of accreted $\mathrm{CO}$ molecules. Moreover, recent theoretical and laboratory studies revealed that recombination of the reactive intermediates, $\mathrm{HCO}, \mathrm{CH}_{3} \mathrm{O}$, and $\mathrm{CH}_{2} \mathrm{OH}$ formed through $\mathrm{H}$-atom addition and abstraction reactions along the $\mathrm{CO}-\mathrm{H}_{2} \mathrm{CO}-$ $\mathrm{CH}_{3} \mathrm{OH}$ chain, also result in the formation of larger complex organic molecules (COMs), like ethylene glycol, glycolaldehyde, methyl formate, and even glycerol in the solid state (Garrod et al. 2006; Woods et al. 2012; Butscher et al. 2015; Fedoseev et al. 2015, 2017; Chuang et al. 2016, 2017).

For the typical pressure and temperature conditions in dark and dense clouds, all of these species except $\mathrm{H}_{2}$ and $\mathrm{He}$ are expected to be fully depleted into the solid state. However, astronomical observations show unexpectedly large abundances of gaseous $\mathrm{CH}_{3} \mathrm{OH}$ and $\mathrm{COMs}$ (Öberg et al. 2010; Bacmann et al. 2012; Cernicharo et al. 2012; Jiménez-Serra et al. 2016). In dark and pre-stellar clouds, it is too cold for thermal desorption to take place; thus, non-thermal 
mechanisms need to be considered to explain the observed gasphase abundances, but effective low-temperature desorption processes remain poorly understood.

Different mechanisms have been proposed, investigated, and discussed, to explain how frozen species can sublimate. Until recently, UV induced photodesorption was considered to be an efficient process for both non-dissociative desorption, i.e., $\mathrm{CO}$ photodesorption, and dissociative processes eventually followed by fragment recombination in the ice or kick-out processes, i.e., $\mathrm{H}_{2} \mathrm{O}$ photodesorption (Andersson \& van Dishoeck 2008; Arasa et al. 2015). However, experiments on methanol ice exhibit substantial molecular fragmentation, including $\mathrm{CH}_{3} \mathrm{O}, \mathrm{CH}_{2} \mathrm{OH}$, and $\mathrm{CH}_{3}$, and with photodesorption rates far too low to transfer substantial amounts of intact $\mathrm{CH}_{3} \mathrm{OH}$ into the gas phase (Bertin et al. 2016; Cruz-Diaz et al. 2016). It is expected that this will also apply to COMs larger than methanol; photodesorption and photodissociation are here clearly connected. A possible way to circumvent fragmentation upon photo-excitation is UV induced codesorption; the excitation of one species results in desorption of another species. For mixed $\mathrm{CO}$ and $\mathrm{N}_{2}$ ices, $\mathrm{N}_{2}$ photocodesorption rate (defined as indirect DIET photodesorption rate) was found to be a highly effective process, i.e., $\sim 10^{-2}$ molecule $\mathrm{cm}^{-2}$ photon $^{-1}$ for photon energies between 7.9 and $9.5 \mathrm{eV}$ (Bertin et al. 2013), but in ice mixtures of $\mathrm{CO}$ and $\mathrm{CH}_{3} \mathrm{OH}$ no methanol could be detected upon $\mathrm{CO}$ excitation (Bertin et al. 2016). In a similar way, low-temperature thermal codesorption of a less volatile species like methanol with $\mathrm{CO}$ was only found to yield very low upper limits of $7 \times 10^{-7}$ molecules per CO (Ligterink et al. 2017). Local heating of an ice mantle induced by the impacting cosmic rays offers another possible mechanism (Léger et al. 1985; Ivlev et al. 2015), but given the high energies involved, it is rather unlikely that this would be a less destructive process than photodesorption, and this process is generally less effective for strongly bound molecules like $\mathrm{CH}_{3} \mathrm{OH}$ than for $\mathrm{CO}$. An interesting alternative is reactive desorption.

Reactive desorption may contribute to the gas-phase enrichment of both simple and complex species; directly, upon formation, formaldehyde, methanol or other COMs are instantly released into the gas phase because of the available excess energy of several $\mathrm{eV}$, or indirectly, by releasing intermediates that cannot be efficiently formed in gas-phase chemical networks, but may act as precursor in COM gas-phase networks. A reactive codesorption process cannot be excluded either, but the excess energy upon bond formation may rapidly dissipate into the ice lattice before being absorbed by another species. These three scenarios may take place simultaneously, but with different efficiencies.

In astrochemical models, the reactive desorption fraction, i.e., the efficiency of product desorption from the surface after reaction, is usually a free parameter, chosen in a range of $0.01-0.1$ to account for the steady-state gas-phase abundances of simple species as observed in the later stages of dense clouds (Garrod et al. 2007; Vasyunin \& Herbst 2013). The initial focus was on energy release upon $\mathrm{H}_{2}$ formation (Duley \& Williams 1993), and later extended to other reactions (Garrod et al. 2007; Vasyunin \& Herbst 2013; Cazaux et al. 2015; Minissale et al. 2016; Fredon et al. 2017). In the latter work, reactive desorption of species was also proposed as a starting point for low-temperature gas-phase formation of COMs (see also Balucani et al. 2015; Taquet et al. 2016;
Rivilla et al. 2017; Vasyunin et al. 2017). Currently, the relative solid-state and gas-phase formation efficiencies for dark cloud conditions are under renewed debate.

So far, there have been few attempts to experimentally study the reactive desorption of the two main $\mathrm{CO}$ hydrogenation products, $\mathrm{H}_{2} \mathrm{CO}$ and $\mathrm{CH}_{3} \mathrm{OH}$. There is a reason for this: the simultaneous occurrence of $\mathrm{H}$-atom induced addition and abstraction reactions, i.e., forward and backward steps along the reaction chain (Figure 1), make it hard to de-convolute the individual reaction steps.

Previously reported experimental desorption fractions for reactive steps in the $\mathrm{CO}$ hydrogenation chain are high. Hidaka et al. (2004) stated that the $\mathrm{H}_{2} \mathrm{CO}$ reactive desorption fraction during hydrogenation could be as high as $60 \%$ to rationalize their finding that the column density of the newly formed $\mathrm{CH}_{3} \mathrm{OH}$ product was less than the consumed column density of the pre-deposited $\mathrm{H}_{2} \mathrm{CO}$, i.e., $\triangle N\left(\mathrm{CH}_{3} \mathrm{OH}\right) / \triangle N\left(\mathrm{H}_{2} \mathrm{CO}\right)<1$. Minissale et al. (2016) found a reactive desorption fraction of $40 \%$ for the single reaction $\mathrm{HCO}+\mathrm{H} \rightarrow \mathrm{CO}+\mathrm{H}_{2}$. This reaction was studied in the sub-monolayer region on a bar of oxidized highly oriented pyrolytic graphite substrate using quadrupole mass spectrometry. For a more astronomically relevant thick ice (several tens of monolayers) these conditions are likely not fully representative and therefore reactive desorption fractions may be substantially different as well.

The work presented here is motivated by the lack of experimentally determined reactive desorption fractions for hydrogenation reactions in multi-layered CO-rich interstellar ice analogs, i.e., for an astrochemically relevant ice thickness of $\sim 0.01 \mu \mathrm{m}$ (Boogert et al. 2015). Rather than trying to disentangle the individual reactions and to measure the individual reaction products in the gas phase, we focus on the full $\mathrm{CO}-\mathrm{H}_{2} \mathrm{CO}-\mathrm{CH}_{3} \mathrm{OH}$ hydrogenation sequence. This is realized by estimating as precisely as possible, the difference in solid-state elemental carbon budget between the amount available from the original species and the resulting solid-state hydrogenation products. We assume that the observed difference is fully or at least partially due to reactive desorption, i.e., the resulting value reflects an upper limit. To perform such experiments, it is necessary to derive setup specific band-strength values in $\mathrm{cm}_{\text {molecule }}{ }^{-1}$ for each of the involved species and their ice mixtures.

In the following section the experimental procedure is described. The results are presented in Section 3. In the final section the astronomical relevance of the data and conclusions are presented.

\section{Experimental}

\subsection{Approach}

The total consumption of elemental carbon of the original species should be equal to the total amount of elemental carbon of the formed species, both in the solid state and, after reactive desorption, in the gas phase:

$$
\begin{aligned}
N_{\text {consumed }}(C)= & \Delta N_{\text {solid }}(\mathrm{CO})=\Delta N_{\text {solid }}\left(\mathrm{H}_{2} \mathrm{CO}\right) \\
& +\Delta N_{\text {solid }}\left(\mathrm{CH}_{3} \mathrm{OH}\right)+N_{\mathrm{RD}}(\mathrm{C}),
\end{aligned}
$$

where $\triangle N_{\text {solid }}(\mathrm{CO})$ is the column density of $\mathrm{CO}$ consumption, $\triangle N_{\text {solid }}\left(\mathrm{H}_{2} \mathrm{CO}\right)\left(\triangle N_{\text {solid }}\left(\mathrm{CH}_{3} \mathrm{OH}\right)\right)$ is the net column density of the $\mathrm{H}_{2} \mathrm{CO}\left(\mathrm{CH}_{3} \mathrm{OH}\right)$ formation, and $N_{\mathrm{RD}}(\mathrm{C})$ is the column density of carbon-bearing species upon reactive desorption mechanism after $\mathrm{H}$-atom bombardment. This means that an 


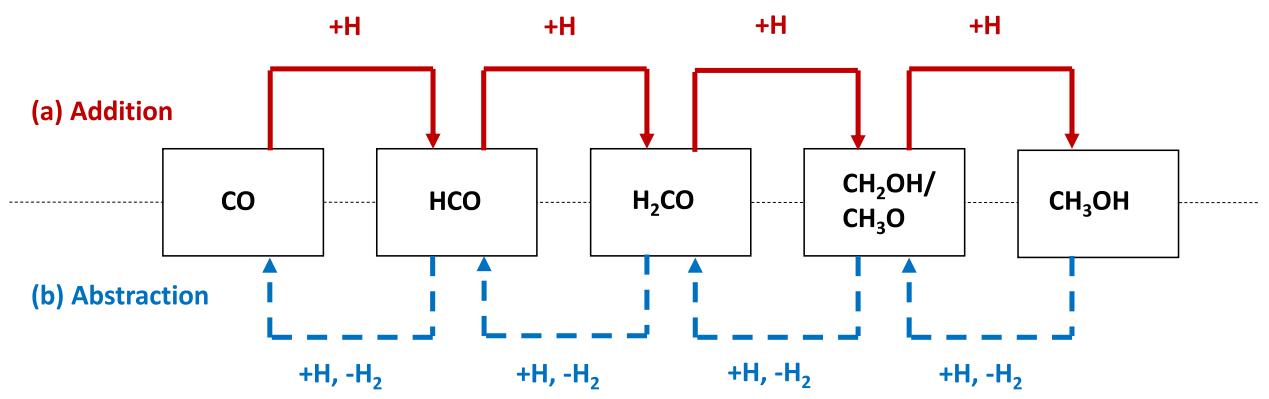

Figure 1. $\mathrm{CO}-\mathrm{H}_{2} \mathrm{CO}-\mathrm{CH}_{3} \mathrm{OH}$ hydrogenation sequence scheme. The solid line and dashed line are for $\mathrm{H}$-atom (a) addition and (b) abstraction reactions, respectively.

upper limit for $N_{\mathrm{RD}}(\mathrm{C}) / N_{\text {consumed }}(\mathrm{C})$ can be derived by comparing accurately the total difference in $\mathrm{CO}$ abundance and $\mathrm{H}_{2} \mathrm{CO}$ and $\mathrm{CH}_{3} \mathrm{OH}$ abundances. In practice, Equation (1) is only an approximation, as it does not take into account other loss channels, such as the formation of other products than $\mathrm{H}_{2} \mathrm{CO}$ and $\mathrm{CH}_{3} \mathrm{OH}$; reactive intermediates can recombine and form COMs larger than methanol, as recently shown by Chuang et al. (2016) and Fedoseev et al. (2017). The impact of this restriction is discussed in Section 3.

\subsection{Experimental Setup}

All experiments are performed using SURFRESIDE ${ }^{2}$, an ultra-high vacuum setup fully optimized to study non-energetic atom addition reactions in interstellar ice analogs at cryogenic temperatures. Details of the design and operation of SURFRESIDE $^{2}$ are available from Ioppolo et al. (2013) and Fedoseev et al. (2016). The base pressure in the main chamber is $\sim 10^{-10}$ mbar, and the corresponding $\mathrm{H}_{2} \mathrm{O}$ contamination through background gas accretion is negligible $(<6.3 \times$ $10^{10}$ molecule $\mathrm{cm}^{-2} \mathrm{~s}^{-1}$ ). A gold-plated copper substrate is mounted in the center of the main chamber and cooled by a recently upgraded closed-cycle helium cryostat that allows to vary the substrate temperature between 8 and $450 \mathrm{~K}$. A silicon diode is used to monitor the temperature with $0.5 \mathrm{~K}$ absolute accuracy. It should be noted that the temperatures used in the present manuscript are about $\sim 2 \mathrm{~K}$ lower than the corresponding numbers used in Fuchs et al. (2009) new and more precise thermal sensors were installed on the substrate. Gaseous species, i.e., $\mathrm{H}_{2} \mathrm{CO}$ obtained by thermal decomposition of paraformaldehyde (Sigma-Aldrich, $95 \%$ ) at $60^{\circ} \mathrm{C}-80{ }^{\circ} \mathrm{C}$ under vacuum, $\mathrm{CH}_{3} \mathrm{OH}$ purified through multiple freeze-pump-thaw cycles and CO (Linde 2.0), are admitted into the UHV chamber through high-precision leak valves mounted under an angle of $22^{\circ}$ from the substrate surface normal. The ices are grown with sub-monolayer precision with $\mathrm{CO}, \mathrm{H}_{2} \mathrm{CO}$ and $\mathrm{CH}_{3} \mathrm{OH}$ deposition rates of $\sim 1.7 \times 10^{12}, \sim 1.4 \times 10^{12}$ and $\sim 2.2 \times$ $10^{12}$ molecules $\mathrm{cm}^{-2} \mathrm{~s}^{-1}$, respectively. The corresponding ice column densities for $\mathrm{CO}, \mathrm{H}_{2} \mathrm{CO}$, and $\mathrm{CH}_{3} \mathrm{OH}$ are $\sim 6.0 \times 10^{15}$, $\sim 5.0 \times 10^{15}$, and $\sim 8.0 \times 10^{15}$ molecules $\mathrm{cm}^{-2}$, respectively. The details of the exact deposition rate calculations are provided later.

After a preset ice thickness of the precursor species is realized, H-atoms are introduced using a Hydrogen Atom Beam Source (Tschersich 2000), mounted in a second UHV chamber. A nose-shape quartz pipe is placed along the path to efficiently quench and thermalize excited $\mathrm{H}$-atoms and nondissociated molecules through multiple collisions with the walls of the pipe. The used $\mathrm{H}$-atom flux in this work amounts to $\sim 8 \times 10^{12}$ atoms cm $\mathrm{cm}^{-2} \mathrm{~s}^{-1}$ with an absolute uncertainty of
$<50 \%$ (Ioppolo et al. 2013) and $\mathrm{H}$-atoms reach the surface under an incident angle of $45^{\circ}$ from the substrate surface normal.

The ice composition is monitored in situ, before and during H-atom bombardment by Fourier Transform ReflectionAbsorption InfraRed Spectroscopy in the range from 700 to $4000 \mathrm{~cm}^{-1}$, with $1 \mathrm{~cm}^{-1}$ resolution. The ice column density $N$ in $\mathrm{cm}^{-2}$ is derived from a modified Beer's law:

$$
N=\frac{\ln 10 \cdot \int \operatorname{Abs}(\nu) d \nu}{A^{\prime}},
$$

where $\operatorname{Abs}(\nu)$ is the band absorbance, $d \nu$ is the wavenumber differential in $\mathrm{cm}^{-1}$, and $A^{\prime}$ is the calibrated band strength in $\mathrm{cm}$ molecule $^{-1}$ in reflection mode. This RAIR band strength cannot be taken from the literature data available for the IR transmission spectroscopy, as the signals obtained in reflection are enhanced through substrate dipole couplings. Moreover, the determination of RAIR band strengths from transmission values cannot be realized by only compensating for different effective IR pathways in the ice. Therefore, a series of extra experiments (see Section 2.3) has been performed to determine the band strength for each of the involved species for our specific experimental settings by using the interference pattern of a $\mathrm{HeNe}$ laser that is reflected from the growing ice sample at 10 K (Baratta \& Palumbo 1998; Brunetto et al. 2008; Fulvio et al. 2009; Bouilloud et al. 2015). For pure ice the absolute column density is calculated by the equation:

$$
N=\frac{d \cdot \rho \cdot N_{a}}{M},
$$

where $d$ is the thickness of ice in $\mathrm{nm}, \rho$ is the density in $\mathrm{g} \mathrm{cm}^{-3}$, $N_{a}$ is the Avogadro's constant $\left(6.022 \times 10^{23} \mathrm{~mol}^{-1}\right)$, and $M$ is the molar mass of the species. The ice thickness ( $\left.D_{\text {growing }}\right)$ is experimentally determined by laser refractive interference,

$$
D_{\text {growing }}=k \times \frac{\lambda}{2 n \cdot \cos \left(\theta_{f}\right)},
$$

where $\lambda=632.8 \mathrm{~nm}$ is the HeNe laser wavelength, $n$ is the refractive index of a specific ice, $\theta_{f} \cong 3^{\circ}$ is the angle of refraction in the ice in degrees, and $k$ is the number of involved fringes (Hollenberg \& Dows 1961; Westley et al. 1998). The exact band-strength values may vary with changing ice composition, structure, and temperature. The reported absolute uncertainty of this method is $5 \%$, a value that is largely determined by the density and refractive index uncertainty (Baratta \& Palumbo 1998; Fulvio et al. 2009). Moreover, as the same technique is used to determine $\mathrm{CO}, \mathrm{H}_{2} \mathrm{CO}$ and $\mathrm{CH}_{3} \mathrm{OH}$ 

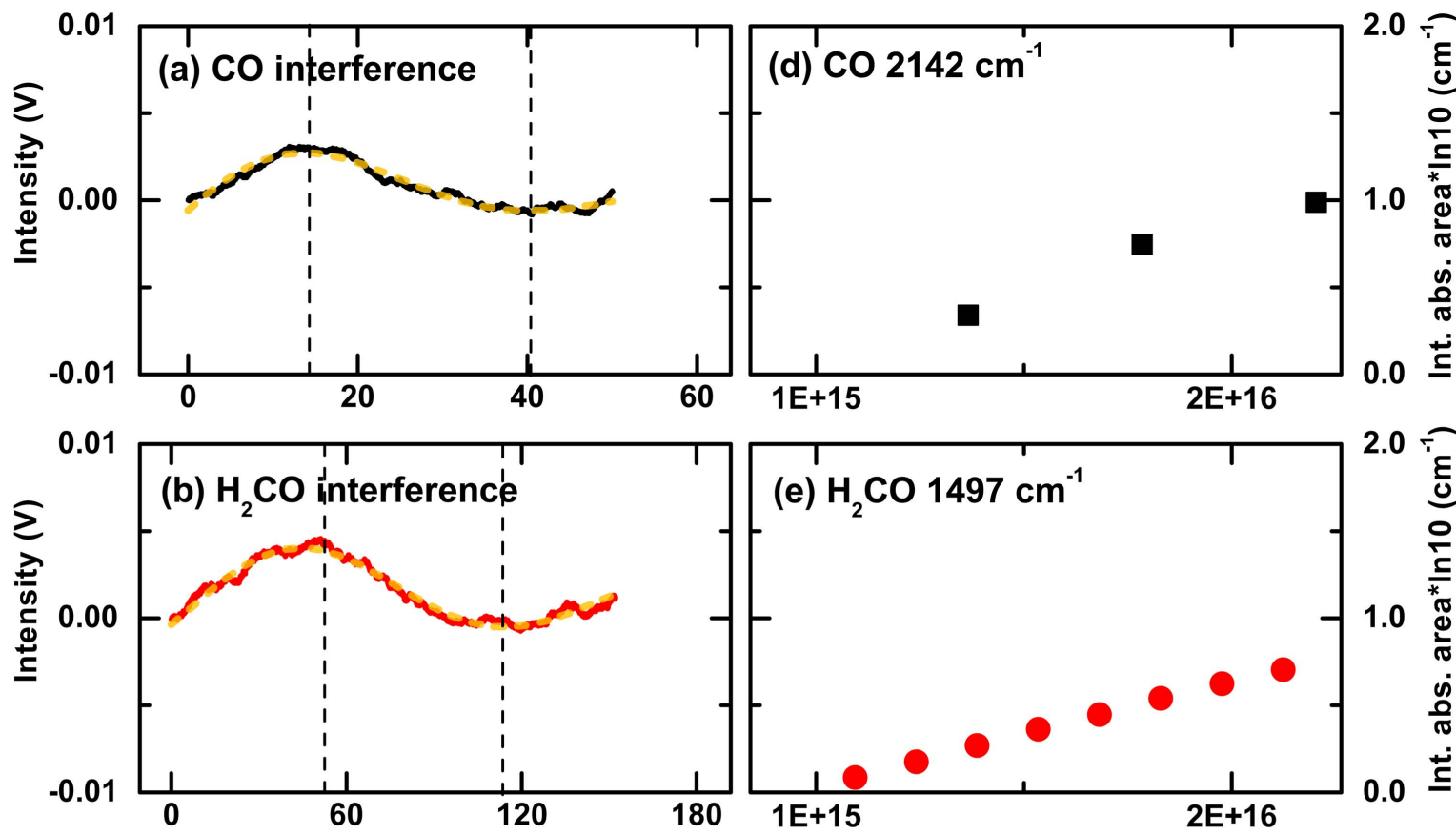

2.0
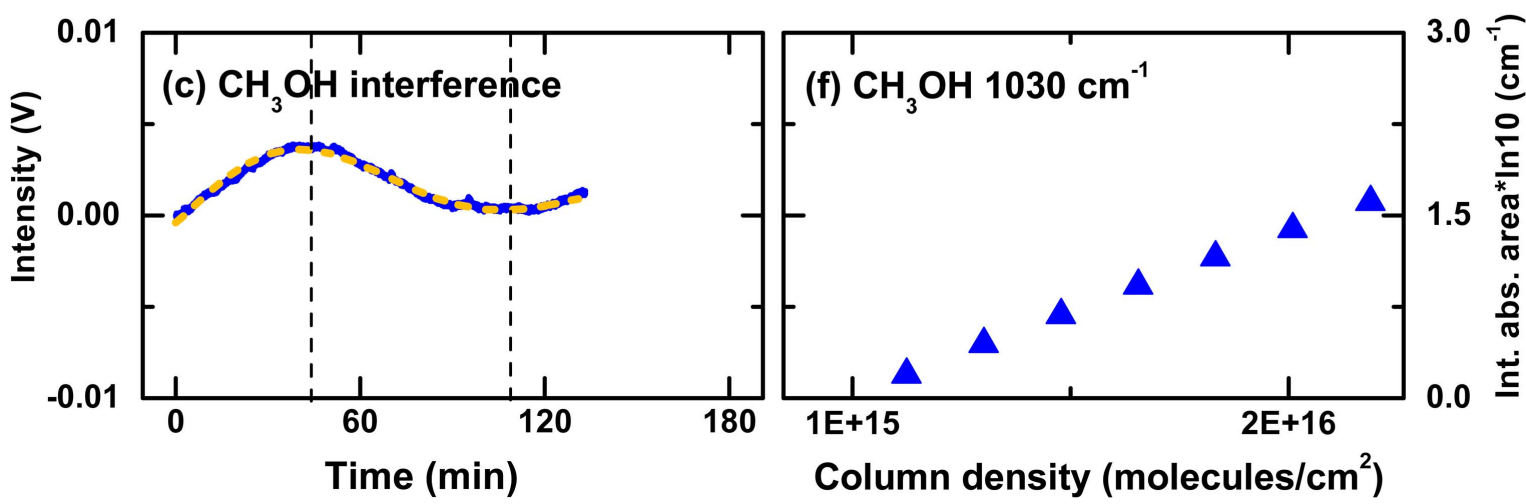

Figure 2. Left: typical examples of the obtained interference fringes as function of time and their corresponding sinusoidal fittings (yellow dashed line) during $10 \mathrm{~K}$ substrate deposition of pure (a) $\mathrm{CO}$, (b) $\mathrm{H}_{2} \mathrm{CO}$, and (c) $\mathrm{CH}_{3} \mathrm{OH}$. The vertical dashed lines (black) indicate the time for maximum and minimum amplitude. Right: the integrated absorption area for deposited (d) $\mathrm{CO}\left(2142 \mathrm{~cm}^{-1}\right.$ band), (e) $\mathrm{H}_{2} \mathrm{CO}\left(1497 \mathrm{~cm}^{-1}\right.$ band) and (f) $\mathrm{CH}_{3} \mathrm{OH}\left(1030 \mathrm{~cm}^{-1}\right.$ band) as a function of column density for the first 7 minutes of deposition.

band strengths, the relative error between values is expected to be lower. This makes it possible, in principle, to establish the obtained $N_{\mathrm{RD}}(\mathrm{C}) / N_{\text {consumed }}(\mathrm{C})$ with high confidence, even when chemistry changes relative ice compositions.

\subsection{Band Strength Measurement for Pure Ices}

The left-hand panel of Figures 2(a)-(c) shows the HeNe laser interference pattern that changes with time as the ice thickness increases upon deposition of $\mathrm{CO}, \mathrm{H}_{2} \mathrm{CO}$, and $\mathrm{CH}_{3} \mathrm{OH}$ onto the $10 \mathrm{~K}$ substrate. One single fringe is typically observed for the low-deposition rates used in this study. Ice density $(\rho)$ and refractive index $(n)$ may vary for different conditions (Bossa et al. 2015). It is important to note that the precise ice density in the amorphous phase is generally unknown for the species studied in this work. Here, the commonly accepted values in literature are taken as good approximate values. For $\mathrm{CO}$, the ice density reported by Roux et al. (1980) at $20 \mathrm{~K}$ is used. Their deposition conditions may have been different from those in our work. For $\mathrm{H}_{2} \mathrm{CO}$, no density value has been reported in the solid phase, thus the value measured in liquid phase is employed (Weast \& Astle 1985). For $\mathrm{CH}_{3} \mathrm{OH}$, the ice density is derived from the value available for its crystalline structure (Mate et al. 2009). Based on the density and refractive index values summarized in Bouilloud et al. (2015) $0.80 \pm$ $0.01 \mathrm{~g} \mathrm{~cm}^{-3}$ and $1.25 \pm 0.03$ for $\mathrm{CO}, 0.81 \pm 0.03 \mathrm{~g} \mathrm{~cm}^{-3}$ and $1.33 \pm 0.04$ for $\mathrm{H}_{2} \mathrm{CO}$, and $1.01 \pm 0.03 \mathrm{~g} \mathrm{~cm}^{-3}$ and $1.33 \pm$ 0.04 for $\mathrm{CH}_{3} \mathrm{OH}-\mathrm{CO}, \mathrm{H}_{2} \mathrm{CO}$, and $\mathrm{CH}_{3} \mathrm{OH}$ deposition rates are derived with values of $\sim(1.3 \pm 0.1) \times 10^{14}, \sim(4.7 \pm 0.4) \times$ $10^{13}$, and $\sim(5.6 \pm 0.5) \times 10^{13}$ molecules $\mathrm{cm}^{-2} \mathrm{~s}^{-1}$. Note that these values differ in these experiments from the regular hydrogenation settings. The choice of the applied density and refractive index values is not ideal, but given the lack of more precise values, this is the best we can provide. If better values become available, the final ratio of $N_{\mathrm{RD}}(\mathrm{C}) / N_{\text {consumed }}(\mathrm{C})$ can be easily re-evaluated.

The corresponding $\mathrm{CO}, \mathrm{H}_{2} \mathrm{CO}$, and $\mathrm{CH}_{3} \mathrm{OH}$ plots, showing the column density upon ice deposition (horizontal axis) and the increasing IR absorption area (vertical axis) over time are presented in the right-hand panels of Figures 2(d)-(e). As explained in Section 2 (Equation (2)), from these plots the $A^{\prime}$, band-strength value, can be derived from molecule specific RAIR bands, following a linear fit. The fitted slopes for (d) $\mathrm{CO}\left(2142 \mathrm{~cm}^{-1}\right)$, (e) $\mathrm{H}_{2} \mathrm{CO}\left(1497 \mathrm{~cm}^{-1}\right)$, and (f) $\mathrm{CH}_{3} \mathrm{OH}\left(1030 \mathrm{~cm}^{-1}\right)$ yield 
absorption strength values $A^{\prime}$ of $(5.2 \pm 0.3) \times 10^{-17}$, $(3.2 \pm 0.3) \times 10^{-17}$, and $(7.1 \pm 0.6) \times 10^{-17} \mathrm{~cm} \mathrm{molecule}^{-1}$, respectively. It should be noted that these values are only safe to use for identical experimental circumstances, i.e., identical IR incident angles, surface materials, etc.

Kerkhof et al. (1999) showed that the band strength of methanol in an ice mixture of $\mathrm{CH}_{3} \mathrm{OH}: \mathrm{CO}_{2}(1: 1)$ and in pure $\mathrm{CH}_{3} \mathrm{OH}$ ice does not vary. We checked this by performing a set of control experiments in which the $\mathrm{CO}, \mathrm{H}_{2} \mathrm{CO}$, and $\mathrm{CH}_{3} \mathrm{OH}$ band-strength values are compared with those derived in $\mathrm{CO}: \mathrm{H}_{2} \mathrm{CO}$ (1:1), $\mathrm{CO}: \mathrm{CH}_{3} \mathrm{OH}(1: 1)$, and $\mathrm{CO}: \mathrm{H}_{2} \mathrm{CO}: \mathrm{CH}_{3} \mathrm{OH}$ (1:1:1) mixed ices. This is realized in the following way. At first, a constant deposition rate of $\mathrm{CO}$ molecules is used through one of the dosing lines. Then, sequentially, $\mathrm{H}_{2} \mathrm{CO}$ and $\mathrm{CH}_{3} \mathrm{OH}$ are introduced through other dosing lines growing an ice mixture during co-deposition. Each time a new species is allowed into the main chamber, and any changes in the $\mathrm{CO}$ absorbance integral area are carefully monitored. Then, in a similar way, changes in the $\mathrm{H}_{2} \mathrm{CO}$ and $\mathrm{CH}_{3} \mathrm{OH}$ absorbance integral area are measured. These changes are linearly correlated with their increasing column densities. From this, it is found that the $\mathrm{CO}, \mathrm{H}_{2} \mathrm{CO}$, and $\mathrm{CH}_{3} \mathrm{OH}$ band strengths are rather constant, with variations that do not exceed $2 \%$ in $\mathrm{CO}$, $\mathrm{CO}: \mathrm{H}_{2} \mathrm{CO}(1: 1), \mathrm{CO}: \mathrm{CH}_{3} \mathrm{OH}(1: 1)$, and $\mathrm{CO}: \mathrm{H}_{2} \mathrm{CO}: \mathrm{CH}_{3} \mathrm{OH}$ $(1: 1: 1)$ ices. RAIR spectra are used only as long as signals are far from saturation, to guarantee a linear correlation with the corresponding column densities (Teolis et al. 2007).

\section{Results and Discussion}

\subsection{Elemental Carbon Budget in CO Hydrogenation Experiments}

Figure 3 presents RAIR difference spectra obtained after hydrogenation of pre-deposited $\mathrm{CO}$ ice for 180 minutes by an $\mathrm{H}$-atom flux of $\sim 8 \times 10^{12}$ atoms cm $\mathrm{s}^{-2}$ at (a) $10 \mathrm{~K}$, (b) $12 \mathrm{~K}$, and (c) $14 \mathrm{~K}$, respectively. The negative peak at $2142 \mathrm{~cm}^{-1}$ shows the consumption of the originally predeposited $\mathrm{CO}$ ice, and the positive peaks indicate the formation of two newly formed main products, i.e., $\mathrm{H}_{2} \mathrm{CO}(1727,1497$, and $\left.1250 \mathrm{~cm}^{-1}\right)$ and $\mathrm{CH}_{3} \mathrm{OH}\left(1030 \mathrm{~cm}^{-1}\right)$. Very similar results have been reported and discussed extensively in previous studies of Watanabe \& Kouchi (2002) and Fuchs et al. (2009).

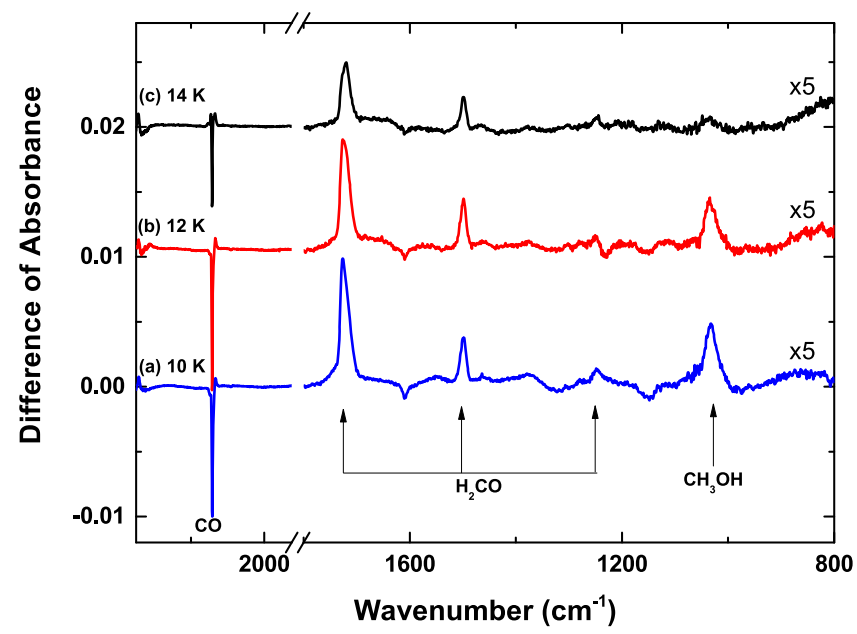

Figure 3. RAIR difference spectra obtained after the exposure of $6 \times$ $10^{15}$ molecules $\mathrm{cm}^{-2}$ pre-deposited $\mathrm{CO}$ to an $\mathrm{H}$-atom flux of $\sim 8 \times$ $10^{12}$ atoms $\mathrm{cm}^{2} \mathrm{~s}^{-1}$ for 180 minutes at (a) $10 \mathrm{~K}$, (b) $12 \mathrm{~K}$, and (c) $14 \mathrm{~K}$. Negative and positive signals reflect net consumption and formation, respectively.

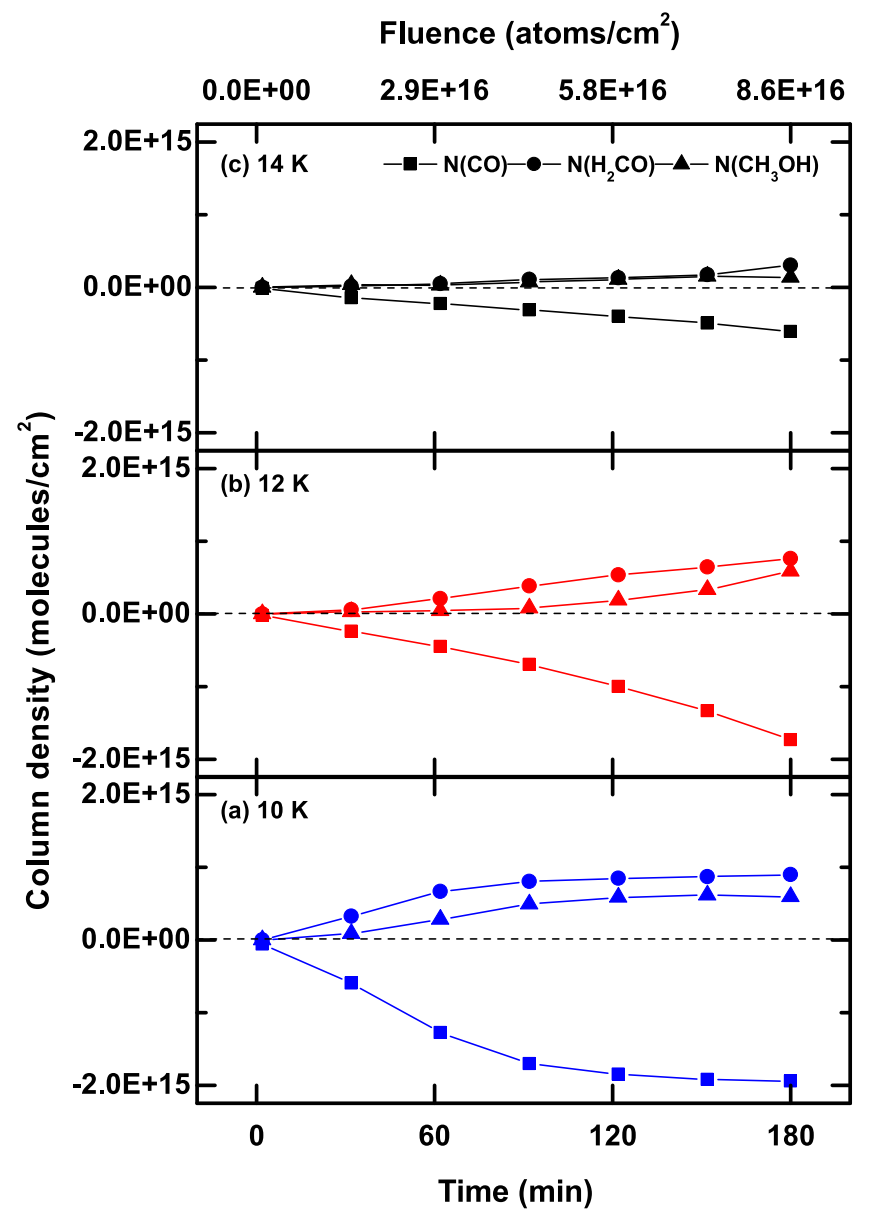

Figure 4. Evolution of the surface column density of $\mathrm{CO}, \mathrm{H}_{2} \mathrm{CO}$, and $\mathrm{CH}_{3} \mathrm{OH}$ during a $\mathrm{CO}$ hydrogenation experiment with an $\mathrm{H}$-atom flux of $\sim 8 \times 10^{12}$ atoms cm $\mathrm{s}^{-1}$ over 180 minutes at (a) $10 \mathrm{~K}$, (b) $12 \mathrm{~K}$, and (c) $14 \mathrm{~K}$, respectively.

No entrapment of the formed intermediate radicals such as $\mathrm{HCO}, \mathrm{CH}_{3} \mathrm{O}$, and $\mathrm{CH}_{2} \mathrm{OH}$ is found, as these easily react with free $\mathrm{H}$-atoms or other radical species.

Figure 4 shows the changing column density obtained from the integrated RAIR absorption areas of the $\mathrm{CO}\left(2142 \mathrm{~cm}^{-1}\right), \mathrm{H}_{2} \mathrm{CO}$ $\left(1497 \mathrm{~cm}^{-1}\right)$, and $\mathrm{CH}_{3} \mathrm{OH}\left(1030 \mathrm{~cm}^{-1}\right)$ signals during $\mathrm{H}$-atom accretion. The negative $\mathrm{CO}$ consumption peak at $10 \mathrm{~K}$ clearly saturates due to the limited penetration depth of $\mathrm{H}$-atoms impacting on the surface. This observation is in agreement with previous findings (Fuchs et al. 2009), indicating that the CO consumption rate exhibits a strong temperature dependence; a lower temperature results in a higher $\mathrm{CO}$ conversion rate, fully in line with the proposed $\mathrm{CO}-\mathrm{H}_{2} \mathrm{CO}-\mathrm{CH}_{3} \mathrm{OH}$ reaction findings presented in the literature (Watanabe et al. 2004; Fuchs et al. 2009). This temperature dependence is explained by the different life (i.e., residence) time of $\mathrm{H}$-atoms on the ice surface before desorbing from the ice surface or recombining to $\mathrm{H}_{2}$ through interactions with other $\mathrm{H}$-atoms. At $10 \mathrm{~K}$ and after 120 minutes of $\mathrm{H}$-atom exposure, the $\mathrm{CO}$ depletion behavior starts slowing down, reaching a maximum value at approximately $2 \times 10^{15}$ molecules $\mathrm{cm}^{-2}$ (180 minutes), reflecting that only the few upper layers of $\mathrm{CO}$ molecules are accessible to accreting H-atoms.

In Figure 5, the effective RD related column densities are shown for three different ice temperatures for 180 minutes $\mathrm{H}$-atom 
Fluence (atoms $/ \mathrm{cm}^{2}$ )

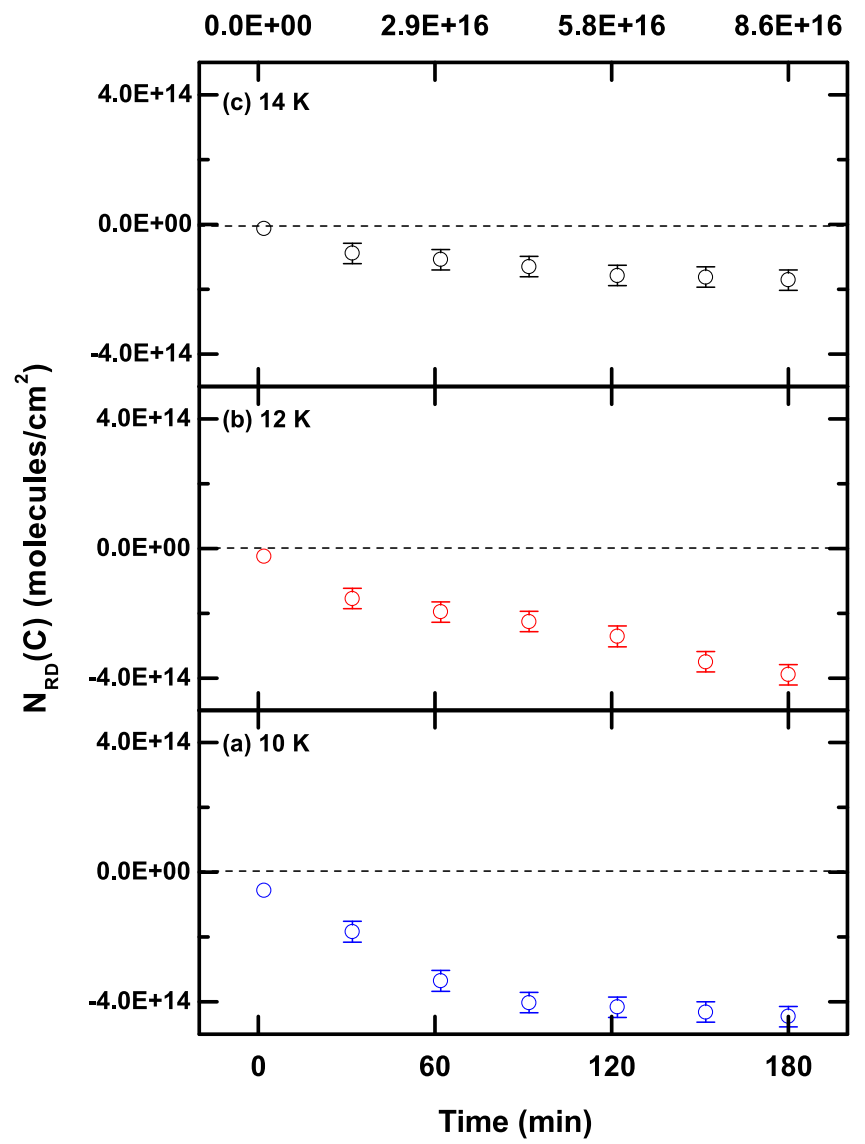

Figure 5. Evolution of the column density of the reactive desorption species, $N_{\mathrm{RD}}(\mathrm{C})$, during a $\mathrm{CO}$ hydrogenation experiment with an $\mathrm{H}$-atom flux of $\sim 8 \times 10^{12}$ atoms cm $\mathrm{s}^{-1}$ over 180 minutes at (a) $10 \mathrm{~K}$, (b) $12 \mathrm{~K}$, and (c) $14 \mathrm{~K}$, respectively.

bombardment. The increasing loss reflects that the sum of $\mathrm{H}_{2} \mathrm{CO}$ and $\mathrm{CH}_{3} \mathrm{OH}$ abundances is less than the amount of consumed $\mathrm{CO}$ molecules. At 180 minutes, the $N_{\mathrm{RD}}(\mathrm{C})$ value reaches $\sim 4.5 \times$ $10^{14}, \sim 3.9 \times 10^{14}$, and $\sim 1.7 \times 10^{14}$ molecules $\mathrm{cm}^{-2}$ for $10 \mathrm{~K}$, $12 \mathrm{~K}$, and $14 \mathrm{~K}$, respectively. As discussed in Equation (1), $N_{\mathrm{RD}}(\mathrm{C})$ reflects all products that are not recorded by the RAIRS technique in the solid state, i.e., this variable includes both the effect of reactive desorption and other elemental carbon loss channels, such as the formation of COMs with two, three, or more carbon atoms. However, the expected final abundances of these COMs cannot account for more than a few percent of the consumed CO molecules, as discussed in Fedoseev et al. (2017). Moreover, their $\mathrm{CO}$ stretching vibration modes are very similar to the $\mathrm{CO}$ stretching vibration modes used here for the $\mathrm{CH}_{3} \mathrm{OH}$ column densities calculations; the smaller fraction of carbon atoms conserved in the formed larger COMs is actually already contributing to the $\mathrm{CH}_{3} \mathrm{OH}$ column densities. Non-overlapping (and generally weaker) IR absorption features of COMs, i.e., around $860 \mathrm{~cm}^{-1}$ for glycolaldehyde and ethylene glycol are not visible, yielding upper limits of the order of $\sim 5 \times 10^{13}$ molecules $\mathrm{cm}^{-2} \mathrm{~s}^{-1}$, i.e., $<3 \%$ of the consumed $\mathrm{CO}$ column density. It should be noted that previous studies on solidstate COM formation by Chuang et al. (2016), Chuang et al. (2017) and Fedoseev et al. (2017) were performed in co-deposition modus that are assumed to simulate interstellar ice conditions in a more representative way.

In Figure 6, the obtained upper limits of $N_{\mathrm{RD}}(\mathrm{C}) / N_{\text {consumed }}(\mathrm{C})$ ratios are summarized for two different time periods: from the start to the end (0-180 minutes) and from 60-180 minutes. These ratios must be strictly treated as upper limits of the reactive desorption fraction for the performed hydrogenation experiments. The abundances obtained at the end of the $\mathrm{CO}$ ice hydrogenation experiments after 180 minutes of $\mathrm{H}$-atom bombardment are used for the calculations (black column in Figure 6), as here the largest amounts with reaction products are reached. This results in the best peak-to-noise ratios and therefore the lowest uncertainties. The resulting $N_{\mathrm{RD}}(\mathrm{C}) / N_{\text {consumed }}(\mathrm{C})$ fractions are $0.23 \pm 0.02,0.22 \pm 0.02$ and $0.28 \pm 0.05$ for $10 \mathrm{~K}, 12 \mathrm{~K}$, and $14 \mathrm{~K}$, respectively. The averaged RD fraction $\left(N_{\mathrm{RD}}(\mathrm{C}) / N_{\text {consumed }}(\mathrm{C})_{10-14 \mathrm{~K}}\right)$ amounts to $0.24 \pm 0.02$ for overall 180 minutes.

A detailed analysis of the data presented in Figure 5 shows that $N_{\mathrm{RD}}(\mathrm{C})$ does not decrease linearly with time; roughly during the first 60 minutes, the decrease is faster (for all three investigated temperatures). This may hint at startup effects, linked to structural weaknesses in the top surface layers because of any loosely bound $\mathrm{CO}$ molecules that get off much easier without the need of reactive desorption, for example, upon a collisional impact. For the period from 60 to 180 minutes, the $N_{\mathrm{RD}}(\mathrm{C})$ decrease is much more linear. To exclude any perturbing contributions, therefore, the elemental carbon loss fraction is also calculated for the values derived between 60 and 180 minutes of $\mathrm{H}$-atom bombardment (red column in Figure 6) resulting in somewhat lower upper values: $0.17 \pm 0.05,0.15 \pm 0.02$, and $0.16 \pm 0.08$ for $10 \mathrm{~K}, 12 \mathrm{~K}$, and $14 \mathrm{~K}$, respectively. The resulting averaged value $(0.16 \pm 0.03)$ amounts to $\sim 70 \%$ of the overall value. The latter value is likely more precise, as it does not include startup effects. However, to stay on the safe side, we report here the overall averaged RD fraction.

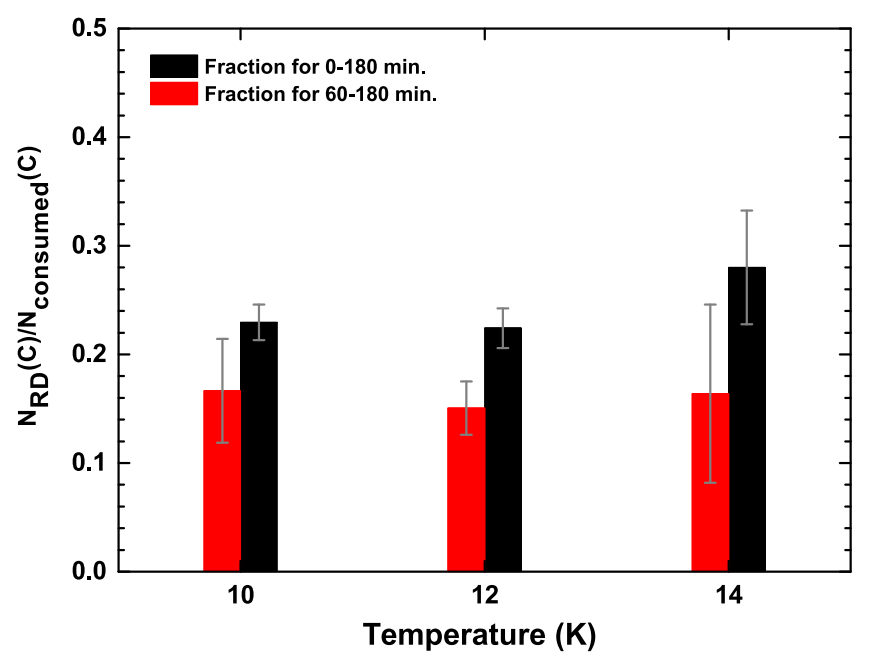

Figure 6. $N_{\mathrm{RD}}(\mathrm{C}) / N_{\text {consumed }}(\mathrm{C})$ ratios obtained after the bombardment of predeposited $\mathrm{CO}$ ice with $\sim 8 \times 10^{12} \mathrm{H}$-atoms $\mathrm{cm}^{-2} \mathrm{~s}^{-1}$ for the full 180 minutes (black column) and the data recorded between 60 and 180 minutes (red column) at 10,12 , or $14 \mathrm{~K}$, respectively. 


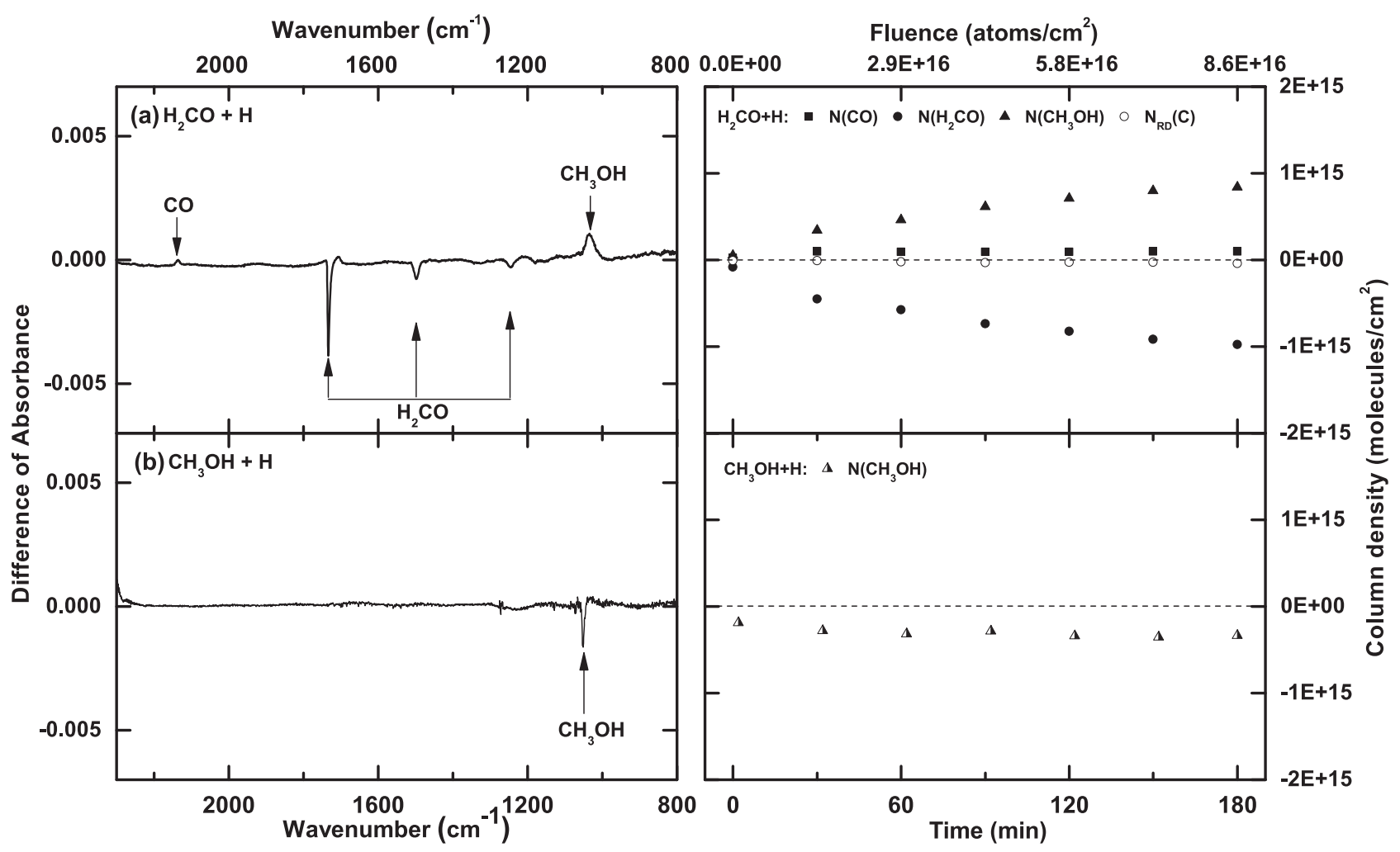

Figure 7. Left: RAIR difference spectra obtained after the exposure of $5 \times 10^{15}$ molecules $\mathrm{cm}^{-2}$ pre-deposited (a) $\mathrm{H}_{2} \mathrm{CO}$ and $8 \times 10^{15}$ molecules $\mathrm{cm}^{-2}$ pre-deposited (b) $\mathrm{CH}_{3} \mathrm{OH}$ to $\sim 8 \times 10^{12} \mathrm{H}$-atoms cm $\mathrm{cm}^{-2} \mathrm{~s}^{-1}$ for 180 minutes at $10 \mathrm{~K}$. Right: evolution of the surface column density of $\mathrm{CO}, \mathrm{H}_{2} \mathrm{CO}$, and $\mathrm{CH}_{3} \mathrm{OH}$ during $\mathrm{H}_{2} \mathrm{CO}$ and $\mathrm{CH}_{3} \mathrm{OH}$ hydrogenation over 180 minutes at $10 \mathrm{~K}$.

\subsection{Elemental Carbon Budget in $\mathrm{H}_{2} \mathrm{CO}$ and $\mathrm{CH}_{3} \mathrm{OH}$ Hydrogenation Experiments}

A very similar set of experiments is used to investigate reactive desorption upon $\mathrm{H}_{2} \mathrm{CO}$ and $\mathrm{CH}_{3} \mathrm{OH}$ hydrogenation. Figure 7 (left panel) presents the RAIR difference spectra obtained after hydrogenation of pre-deposited (a) $\mathrm{H}_{2} \mathrm{CO}$ and (b) $\mathrm{CH}_{3} \mathrm{OH}$ ice for an $\mathrm{H}$-atom flux of $\sim 8 \times 10^{12}$ atoms cm $\mathrm{cm}^{-2}$ for 180 minutes at $10 \mathrm{~K}$. In spectrum (a), the negative peaks at 1727,1497 , and $1250 \mathrm{~cm}^{-1}$ show the depletion of the initially deposited $\mathrm{H}_{2} \mathrm{CO}$, while the positive peaks indicate the formation of newly formed products, i.e., $\mathrm{CO}\left(2142 \mathrm{~cm}^{-1}\right)$ and $\mathrm{CH}_{3} \mathrm{OH}\left(1030 \mathrm{~cm}^{-1}\right)$. The formation of $\mathrm{CO}$ through $\mathrm{H}$-atom abstraction reactions from $\mathrm{H}_{2} \mathrm{CO}$ and of $\mathrm{CH}_{3} \mathrm{OH}$ through $\mathrm{H}$-atom addition reactions to $\mathrm{H}_{2} \mathrm{CO}$ have been reported previously by Hidaka et al. (2004) and Chuang et al. (2016).

In contrast, the $\mathrm{CH}_{3} \mathrm{OH}$ hydrogenation experiments (Figure 7(b)) do not result in any efficient consumption of $\mathrm{CH}_{3} \mathrm{OH}$ and the formation of hydrogenation products. Only a small negative $\mathrm{CH}_{3} \mathrm{OH}$ peak $\left(1050 \mathrm{~cm}^{-1}\right)$ is observed, while no secure identification of other carbon-bearing species can be made. Moreover, the consumption peak accumulates at the very beginning of the $\mathrm{H}$-atom bombardment and as discussed above; this may be due to other processes than reactive desorption. As in the $\mathrm{CO}$ hydrogenation experiments, there is no spectroscopic evidence for radical entrapments due to high reactivity.

The evolving column density of $\mathrm{CO}, \mathrm{H}_{2} \mathrm{CO}$, and $\mathrm{CH}_{3} \mathrm{OH}$ during $\mathrm{H}$-atom exposure with time is shown in the right-hand panel of Figure 7. The consumed $N\left(\mathrm{H}_{2} \mathrm{CO}\right)$ saturates at $\sim 1 \times 10^{15}$ molecules $\mathrm{cm}^{-2}$ and is possibly limited by the $\mathrm{H}$-atom penetration depth as discussed before. However, $N\left(\mathrm{CH}_{3} \mathrm{OH}\right)$ saturates immediately, indicating the structural ice changes described before occurring on the surface comprising of $\mathrm{CH}_{3} \mathrm{OH}$ molecules. As discussed for the $\mathrm{CO}$ hydrogenation experiments, the column density of the missing carbon during the first 60 minutes of $\mathrm{H}$-atom bombardment likely includes other unwanted desorption processes. Following the same approach as described in Section 3.2, an extended calculation of the $\mathrm{H}_{2} \mathrm{CO}$ hydrogenation experiment shows that the sum of the consumption of $\mathrm{H}_{2} \mathrm{CO}$ and the production of $\mathrm{CO}$ and $\mathrm{CH}_{3} \mathrm{OH}$ is very small; $\sim 2.0 \times 10^{13}$ molecules $\mathrm{cm}^{-2}$, i.e., $4 \%$ with respect to the $\mathrm{CO}$ hydrogenation experiments at $10 \mathrm{~K}$. In the $\mathrm{CH}_{3} \mathrm{OH}$ hydrogenation experiments, the $N_{\mathrm{RD}}(\mathrm{C})$ originates only from the consumption of $N\left(\mathrm{CH}_{3} \mathrm{OH}\right)$ due to a poor detection of $\mathrm{H}_{2} \mathrm{CO}$ and results in $4 \%$ with respect to the $\mathrm{CO}$ hydrogenation experiments at $10 \mathrm{~K}$. These small signals with large uncertainty complicate the determination of reactive desorption fractions. Future work is needed to provide more precise $\mathrm{RD}$ efficiencies for $\mathrm{H}_{2} \mathrm{CO}$ and $\mathrm{CH}_{3} \mathrm{OH}$.

\section{Astrophysical Implication and Conclusions:}

The astronomical relevance of this work is that the $\mathrm{RD}$ fraction used in astrochemical models (for CO hydrogenation, but likely also more general) can be based on an experimentally determined value. The laboratory data obtained here indicate that the sum of consumption and production of carbon-bearing species along the $\mathrm{CO}$ hydrogenation in the solid state is not zero. The overall reactive desorption fraction $f_{\text {overall }}=$ $N_{\mathrm{RD}}(\mathrm{C}) / N_{\text {consumed }}(C)_{10-14 \mathrm{~K}}=0.24 \pm 0.02$ for CO hydrogenation into $\mathrm{CH}_{3} \mathrm{OH}$ is obtained under the assumption that the missing carbon fraction is fully or largely explained by the reactive desorption of hydrogenation products into the gas phase. This value is in the best case an upper limit and the 
actual effect of reactive desorption may be much smaller, in line with value derived from 60-180 minutes experiments.

The obtained upper limit is the cumulative effect of all involved reactions. This includes $\mathrm{H}$-atom addition and $\mathrm{H}$-atom abstraction reactions with the stable species $\left(\mathrm{CO}, \mathrm{H}_{2} \mathrm{CO}\right.$, and $\left.\mathrm{CH}_{3} \mathrm{OH}\right)$ as well as $\mathrm{H}$-atom reactions with intermediate radicals ( $\mathrm{HCO}, \mathrm{CH}_{3} \mathrm{O}, \mathrm{CH}_{2} \mathrm{OH}$ ). Although the resulting number is an overall value, it is possible to derive the effective desorption fraction for a single $\mathrm{H}$-atom reaction $\left(f_{\text {single }}\right)$ by assuming an identical efficiency for each reaction in the hydrogenation process (Garrod et al. 2007). The total fraction of the species left on the surface, i.e., $\left(1-f_{\text {overall }}\right)$, is equal to the left fraction of a single reaction i.e., $\left(1-f_{\text {single }}\right)$, to the power $n$ :

$$
\left(1-f_{\text {single }}\right)^{n}=1-f_{\text {overall }},
$$

where $n$ is the number of reactions in the hydrogenation scheme. $f_{\text {single }}$ can be obtained from the $f_{\text {overall }}$ measured in our experiments and depends on the average number of $\mathrm{H}$-atom addition and abstraction steps occurring upon conversion of $\mathrm{CO}$ into $\mathrm{CH}_{3} \mathrm{OH}$ (see Figure 1). For an astrochemical simulation in which only $\mathrm{H}$-atom addition reactions are taken into account, the number of steps resulting in the conversion of $\mathrm{CO}$ molecules into $\mathrm{CH}_{3} \mathrm{OH}$ is four $(n=4)$ :

$$
\mathrm{CO} \rightarrow \mathrm{HCO} \rightarrow \mathrm{H}_{2} \mathrm{CO} \rightarrow \mathrm{CH}_{3} \mathrm{O} \rightarrow \mathrm{CH}_{3} \mathrm{OH} .
$$

According to Equation (5), this gives $f_{\text {single }}$ is $\leqslant 0.066 \pm 0.006$. This value can be treated as the upper limit for the effective reactive desorption fraction at each of the $\mathrm{H}$-atom addition steps. For a scenario in which $\mathrm{H}$-atom induced abstraction reactions are also considered, this value further decreases. Assuming that both addition and abstraction reactions contributed equally efficient to the overall reactive desorption fraction along the hydrogenation sequence, e.g.,

$$
\begin{aligned}
& \mathrm{CO} \rightarrow \mathrm{HCO} \rightarrow \mathrm{CO} \rightarrow \mathrm{HCO} \rightarrow \mathrm{H}_{2} \mathrm{CO} \rightarrow \mathrm{HCO} \rightarrow \\
& \mathrm{H}_{2} \mathrm{CO} \rightarrow \mathrm{CH}_{3} \mathrm{O} \rightarrow \mathrm{H}_{2} \mathrm{CO} \rightarrow \mathrm{CH}_{3} \mathrm{O} \rightarrow \\
& \mathrm{CH}_{3} \mathrm{OH} \rightarrow \mathrm{CH}_{2} \mathrm{OH} \rightarrow \mathrm{CH}_{3} \mathrm{OH} .
\end{aligned}
$$

The effective reactive desorption fraction per reaction of $f_{\text {single }}$ is $\leqslant 0.023 \pm 0.002$, taking $n=12$. Such effective reactive desorption fractions per hydrogenation reaction can be utilized in the models where both $\mathrm{H}$-atom addition and abstraction steps are incorporated. It should be noted that at the current stage no clear understanding on the number of the involved reaction steps is achieved (Nagaoka et al. 2005; Hidaka et al. 2009; Minissale et al. 2015). In general, a higher number of reaction steps will yield a lower effective reactive desorption fraction per single reaction. Clear data on the relative contribution of the involved $\mathrm{H}$-atom addition and abstraction steps do not exist in the literature and cannot be reliably concluded from the current study.

The effective reactive desorption fractions concluded in both the aforementioned scenarios are well within the $0.01-0.10$ range of reactive desorption fractions currently used as a free parameter in astrochemical models to explain the transfer of species into the gas phase following their formation in the solid state (Garrod et al. 2007; Vasyunin \& Herbst 2013; Balucani et al. 2015; Chang \& Herbst 2016). These values are clearly much lower than the 40\%-60\% values reported earlier for other surfaces, but as discussed before, these involved experiments in the sub-monolayer regime. Values of the order of $0.01-0.1$, however, are large enough to support a solid-state mechanism enhancing abundances of small carbon-bearing species into the gas phase. This is relevant from two points of view. On one hand, it provides an intrinsic non-thermal desorption mechanism that may explain the gas-phase observation of molecules that should be fully frozen out for the low temperatures in cold clouds. Garrod et al. (2007) show that models including chemical desorption only induced by association reactions require a reactive desorption fraction of 0.03 to optimally represent the observed gaseous $\mathrm{CH}_{3} \mathrm{OH}$ abundances for $\mathrm{L} 134 \mathrm{~N}$ (Dickens et al. 2000). On the other hand, RD may offer the necessary precursors for proposed gas-phase reaction networks that result in the formation of complex molecules in addition to COMs already formed in the solid state.

The astronomical take home message is that the experimental results presented here yield an effective reactive desorption fraction for $\mathrm{CO}$ hydrogenation that constrain the desorption efficiency previously used in astrochemical simulations to explain astronomical observations toward pre-stellar cores. The derived values give upper limits and the real effect of RD may be smaller.

This research was funded through a VICI grant of NWO (the Netherlands Organization for Scientific Research), an A-ERC grant 291141 CHEMPLAN, and has been performed within the framework of the Dutch Astrochemistry Network. Financial support by NOVA (the Netherlands Research School for Astronomy) and the Royal Netherlands Academy of Arts and Sciences (KNAW) through a professor prize is acknowledged. G.F. acknowledges the financial support from the European Union's Horizon 2020 research and innovation program under the Marie Sklodowska-Curie grant agreement no. 664931. S.I. acknowledges the Royal Society for financial support and the Holland Research School for Molecular Chemistry (HRSMC) for a travel grant. The described work has benefited a lot from continuing collaborations within the framework of the FP7 ITN LASSIE consortium (GA238258).

\section{ORCID iDs}

K.-J. Chuang (1) https://orcid.org/0000-0001-6877-5046

D. Qasim (i) https://orcid.org/0000-0002-3276-4780

S. Ioppolo (1) https://orcid.org/0000-0002-2271-1781

E. F. van Dishoeck (ib https://orcid.org/0000-0001-7591-1907

H. Linnartz (iD https://orcid.org/0000-0002-8322-3538

\section{References}

Andersson, S., \& van Dishoeck, E. F. 2008, A\&A, 491, 907 Arasa, C., Koning, J., Kroes, G. J., et al. 2015, A\&A, 575, A121 Bacmann, A., Taquet, V., Faure, A., et al. 2012, A\&A, 541, L12 Balucani, N., Ceccarelli, C., \& Taquet, V. 2015, MNRAS, 449, L16 Baratta, G. A., \& Palumbo, M. E. 1998, JOSAA, 15, 3076 Bertin, M., Fayolle, E. C., Romanzin, C., et al. 2013, ApJ, 779, 120 Bertin, M., Romanzin, C., Doronin, M., et al. 2016, ApJL, 817, L12 Boogert, A. C. A., Gerakines, P. A., \& Whittet, D. C. B. 2015, A\&A, 53, 541 Bossa, J. B., Maté, B., Fransen, C., et al. 2015, ApJ, 814, 47 Bouilloud, M., Fray, N., Benilan, Y., et al. 2015, MNRAS, 451, 2145 Brunetto, R., Caniglia, G., Baratta, G., \& Palumbo, M. 2008, ApJ, 686, 1480 Butscher, T., Duvernay, F., Theule, P., et al. 2015, MNRAS, 453, 1587 Cazaux, S., Minissale, M., Dulieu, F., \& Hocuk, S. 2015, A\&A, 585, A55 Cernicharo, J., Marcelino, N., Roueff, E., et al. 2012, ApJL, 759, L43 Chang, Q., \& Herbst, E. 2012, ApJ, 759, 147

Chang, Q., \& Herbst, E. 2016, ApJ, 819, 145

Charnley, S., Tielens, A., \& Rodgers, S. 1997, ApJL, 482, L203 Chuang, K.-J., Fedoseev, G., Ioppolo, S., et al. 2016, MNRAS, 455, 1702 Chuang, K.-J., Fedoseev, G., Qasim, D., et al. 2017, MNRAS, 467, 2552 
Cruz-Diaz, G., Martín-Doménech, R., Muñoz Caro, G., \& Chen, Y. 2016, A\&A, 592, A68

Cuppen, H., van Dishoeck, E., Herbst, E., \& Tielens, A. 2009, A\&A, 508, 275

Cuppen, H. M., Ioppolo, S., Romanzin, C., et al. 2010, PCCP, 12, 12077

Cuppen, H. M., Penteado, E. M., Isokoski, K., et al. 2011, MNRAS, 417, 2809

Dickens, J. E., Irvine, W. M., Snell, R. L., et al. 2000, ApJ, 542, 870

Duley, W., \& Williams, D. 1993, MNRAS, 260, 37

Enoch, M. L., Evans, N. J., II, Sargent, A. I., et al. 2008, ApJ, 684, 1240

Fedoseev, G., Chuang, K.-J., Ioppolo, S., et al. 2017, ApJ, 842, 52

Fedoseev, G., Chuang, K.-J., van Dishoeck, E. F., et al. 2016, MNRAS, 460, 4297

Fedoseev, G., Cuppen, H., Ioppolo, S., et al. 2015, MNRAS, 448, 1288

Fredon, A., Lamberts, T., \& Cuppen, H. M. 2017, ApJ, 849, 125

Fuchs, G., Cuppen, H., Ioppolo, S., et al. 2009, A\&A, 505, 629

Fulvio, D., Sivaraman, B., Baratta, G. A., et al. 2009, AcSpA, 72, 1007

Garrod, R., Hee Park, I., Caselli, P., \& Herbst, E. 2006, FaDi, 133, 51

Garrod, R., Wakelam, V., \& Herbst, E. 2007, A\&A, 467, 1103

Geppert, W., Hellberg, F., Österdahl, F., et al. 2006, Proceedings of the International Astronomical Union, 1, 117

Hasegawa, T. I., Herbst, E., \& Leung, C. M. 1992, ApJS, 82, 167

Hidaka, H., Watanabe, M., Kouchi, A., et al. 2009, ApJ, 702, 291

Hidaka, H., Watanabe, M., Kouchi, A., et al. 2011, PCCP, 13, 15798

Hidaka, H., Watanabe, N., Shiraki, T., et al. 2004, ApJ, 614, 1124

Hiraoka, K., Miyagoshi, T., Takayama, T., et al. 1998, ApJ, 498, 710

Hiraoka, K., Ohashi, N., Kihara, Y., et al. 1994, CPL, 229, 408

Hiraoka, K., Yamashita, A., Yachi, Y., et al. 1995, ApJ, 443, 363

Hollenberg, J., \& Dows, D. 1961, JChPh, 34, 1061

Ioppolo, S., Cuppen, H. M., Romanzin, C., et al. 2008, ApJ, 686, 1474

Ioppolo, S., Cuppen, H. M., Romanzin, C., et al. 2010, PCCP, 12, 12065

Ioppolo, S., Fedoseev, G., Lamberts, T., et al. 2013, RScI, 84, 073112

Ivlev, A., Röcker, T., Vasyunin, A., \& Caselli, P. 2015, ApJ, 805, 59

Jiménez-Serra, I., Vasyunin, A. I., Caselli, P., et al. 2016, ApJL, 830, L6

Kerkhof, O., Schutte, W. A., \& Ehrenfreund, P. 1999, A\&A, 346, 990

Léger, A., Jura, M., \& Omont, A. 1985, A\&A, 144, 147
Ligterink, N. F. W., Walsh, C., Bhuin, R. G., et al. 2017, A\&A, in press (arXiv:1801.04846)

Linnartz, H., Ioppolo, S., \& Fedoseev, G. 2015, IRPC, 34, 205 (arXiv:1507. 02729)

Mate, B., Galvez, O., Herrero, V. J., \& Escribano, R. 2009, ApJ, 690, 486

Minissale, M., Dulieu, F., Cazaux, S., \& Hocuk, S. 2015, A\&A, 585, A24

Minissale, M., Moudens, A., Baouche, S., et al. 2016, MNRAS, 458, 2953

Miyauchi, N., Hidaka, H., Chigai, T., et al. 2008, CPL, 456, 27

Nagaoka, A., Watanabe, N., \& Kouchi, A. 2005, ApJL, 624, L29

Öberg, K., Boogert, A., Pontoppidan, K., et al. 2011, ApJ, 740, 109

Öberg, K., Bottinelli, S., Jørgensen, J., \& van Dishoeck, E. 2010, ApJ, 716,825

Penteado, E. M., Boogert, A. C. A., Pontoppidan, K. M., et al. 2015, MNRAS, 454, 531

Pontoppidan, K. 2006, A\&A, 453, L47

Rivilla, V., Beltrán, M., Cesaroni, R., et al. 2017, A\&A, 598, A59

Roux, J. A., Wood, B. E., Smith, A. M., \& Plyler, R. R. 1980, Int. Rep., AEDC-TR-79, Arnold Engineering Development Center (AEDC), Arnold Air Force Base

Taquet, V., Wirström, E., \& Charnley, S. 2016, ApJ, 821, 46

Teolis, B. D., Loeffler, M. J., Raut, U., et al. 2007, Icar, 190, 274

Tielens, A., \& Hagen, W. 1982, A\&A, 114, 245

Tielens, A., Tokunaga, A., Geballe, T., \& Baas, F. 1991, ApJ, 381, 181 Tschersich, K. G. 2000, JAP, 87, 2565

van Dishoeck, E. F., Herbst, E., \& Neufeld, D. A. 2013, ChRv, 113, 9043

Vasyunin, A., Caselli, P., Dulieu, F., \& Jiménez-Serra, I. 2017, ApJ, 842, 33

Vasyunin, A., \& Herbst, E. 2013, ApJ, 769, 34

Watanabe, N., \& Kouchi, A. 2002, ApJL, 571, L173

Watanabe, N., Nagaoka, A., Shiraki, T., et al. 2004, ApJ, 616, 638

Weast, R. C., \& Astle, M. J. 1985, CRC Handbook of Data on Organic Compounds (Boca Raton, FL: CRC Press), 968

Westley, M., Baratta, G., \& Baragiola, R. 1998, JChPh, 108, 3321

Willacy, K., \& Millar, T. 1998, MNRAS, 298, 562

Woods, P. M., Kelly, G., Viti, S., et al. 2012, ApJ, 750, 19

Zhitnikov, R., \& Dmitriev, Y. 2002, A\&A, 386, 1129 